Running head: DIVORCE, CONFLICT, AND MENTAL HEALTH

Divorce, Conflict, and Mental Health:

How the Quality of Intimate Relationships Is Linked to Post-Divorce Well-being

SARA SYMOENS ${ }^{\mathrm{ab}}$, ELIEN COLMAN $^{\mathrm{a}}$, AND PIET BRACKE $^{\mathrm{a}}$

a Department of Sociology, Ghent University, Ghent, Belgium

$b$ Sara Symoens (corresponding author)

Korte Meer 5

9000 Ghent $(B)$

Tel: $+329 / 2648455$

Fax: $+329 / 2646975$

Sara.Symoens@Ugent.be

Article published in Journal of Applied Social Psychology, ISSN: 1559-1816

This research was supported by the agency for Innovation by Science and Technology (www.iwt.be) 


\title{
Divorce, Conflict, and Mental Health: How the Quality of Intimate Relationships Is \\ Linked to Post-Divorce Well-being
}

\begin{abstract}
Partner relationships, including new relationships after divorce, are found to be beneficial for mental health. However, the impact of their quality remains unclear; this uncertainty applies to past and ongoing relationships between ex-spouses as well. We study the relationship between conflict - in the prior marriage, with the ex-partner, with a new partner-and both positive and negative mental health. Multilevel linear models are carried out on a subsample of 892 divorcees from the dataset "Divorce in Flanders." Living together with a new partner, either in marriage or cohabitation, seems beneficial for mental health, even in cases of (high) conflict. Nevertheless, conflict places a burden on well-being, especially for women in nonmarital relationships. Ongoing conflict with the ex-spouse is also damaging for mental health. In contrast, prior marital conflict does not relate to lower, but to slightly higher, levels of life satisfaction after divorce.
\end{abstract}

Keywords: conflict, divorce, gender, mental health 


\section{Divorce, Conflict, and Mental Health: How the Quality of Intimate Relationships Is Linked to Post-Divorce Well-being}

\section{Introduction}

The relationship between divorce and well-being has been studied extensively. Almost all studies conclude that the divorced report lower levels of mental health and more often exhibit problem drinking and problematic behavior compared to the married (Amato, 2000; Aseltine \& Kessler, 1993; Bracke, 1998; Kalmijn, 2010; Kalmijn \& Monden, 2004; Kitson, 1992; Lucas, 2005; Marks, 1996; Marks \& Lambert, 1998; Shapiro, 1996; Simon \& Marcussen, 1999; Strohschein, McDonough, Monette, \& Shao, 2005). Differences in coping and well-being within the group of the divorced are less studied. The social stress model (Pearlin, Menaghan, Lieberman \& Mullan, 1981) is the dominating model in studies on divorce and mental health. The basis of this model is the idea that life changes such as divorce are inherently stressful and that the differences in stress levels stemming from divorce are due to differences in exposure and vulnerability to stress factors. The most prevalent stressors after divorce include having to face financial restrictions, having to move, having sole custody of children or losing contact with children, and experiencing major reductions in social networks (Amato, 2000; Booth \& Amato, 1991; Fokkema, 2001; Kalmijn \& Broese Van Groenou, 2005; Shapiro \& Lambert, 1999; Terhell, Broese Van Groenou, \& van Tilburg, 2004, 2007; Wang \& Amato, 2000). Although the social stress model has proved its worth, it has two shortcomings. First, as it focuses only on the stressful aspects of divorce, studies mostly use single-sided negative indicators of mental health, neglecting indicators of positive functioning and general life satisfaction. This focus fails to consider divorce as potentially positive, as it may be in cases of marriages characterized by low marital quality (Amato, 2000, Amato \& Hohmann-Marriott, 2007; Marks, 1996; Riessman, 1990; Ross, 
1991; Ryff, 1989; Wheaton, 1990), or in cases where the decision to divorce was a shared decision (Hewitt \& Turrell, 2011). More practically, it ignores an opportunity counselors may have to focus on aspects of well-being other than depression, that is, to stimulate positive functioning in addition to reducing psychological stress. Second, most classical stress studies focus only on post-divorce conditions to explain differences in post-divorce well-being, neglecting the impact prior life circumstances may have (Wheaton, 1990). This paper recognizes the multidimensionality of mental health, and follows the idea that divorce should be studied in context, integrating characteristics of the prior marriage as well.

Although a great deal of literature exists on the positive effects of marriage and marital quality (Proulx, Helms, \& Buehler, 2007) and on the negative effect of marital conflict (Choi \& Marks, 2008), the impact of prior marital quality and conflict on expartners' mental health has been studied less often (Kalmijn \& Monden, 2006; Prigerson, Maciejewski, \& Rosenheck, 1999). An important sub-tradition in literature focuses on social relations after divorce, including conflict with and support from family and friends (Amato, 2000; Aneshensel, 1992; Bracke, 1993; Booth \& Amato, 1991; Dohrenwend \& Dohrenwend, 1976; Pearlin, 1989; Pearlin et al., 1981; Strohschein et al., 2005; Turner, Wheaton, \& Lloyd, 1995; Wheaton, 1980, 1983). In these studies, the new partner relationship especially is found to be particularly beneficial to mental health. However, few studies differentiate between post-divorce marital relationships and cohabiting relationships. Prior research indicates that there is an overall benefit to marriage; this raises the question of whether this is also the case in new relationships after divorce. Moreover, consideration of the ex-partner is almost totally absent in studies. Nevertheless, ex-partners still have to make or follow up on many arrangements together after the divorce (division of goods, major life changes concerning children, payment of alimony, etc.), keeping them tied to each other. This contact can be 
intense and long lasting, particularly when divorcees have joint children. Therefore, the impact on mental health of these ongoing but often undesired relationships is worth studying.

This research focuses on intimate relationships with both the ex-partner and the new partner, and the extent to which conflict is linked to well-being after divorce. We consider (1) how mental health after divorce is related to having a new partner and to the type and quality of that relationship, (2) how it is related to the quality of the prior and current relationship with the ex-partner, and (3) whether gender-differential effects are apparent and/or whether these effects of conflict in intimate relationships depend on the particular indicator of wellbeing. We use data from the project "Divorce in Flanders" (Mortelmans et al., 2011, www.divorceinflanders.be). This is a robust Flemish dataset, designed specifically to study the antecedents and consequences of first divorces. Multiple indicators of mental health are included, as well as information on relationships, relationship quality, and prior marital conflict.

\section{Contextualizing Divorce}

\section{Conflict, Divorce, and Mental Health}

Ample research has been conducted on the positive effect of being in an intimate relationship on multiple life domains, including mental health. Overall, those living together with a partner report higher levels of general well-being than single people, regardless of whether the latter ever have separated, divorced, or widowed (Horwitz, McLaughlin, \& White, 1997; Kim \& Mckenry, 2002). The married, especially, seem to have a mental health advantage. Moreover, most studies show that the married not only fare better in general than the singles, they also do better compared to the never married or cohabiting on different indicators of mental health (Bierman, Fazio, \& Milkie, 2006; Brown, 2000; Horwitz \& White, 1998; Marcussen, 2005), as well as with regard to health-related behavior like substance abuse (Bierman et al., 2006; Marcussen, 2005; Li, Wilsnack, Wilsnack, \& 
Kristjanson, 2010). Other studies, however, have failed to demonstrate this "cohabitation gap" or "marriage effect" (e.g., Musick \& Bumpass, 2012). Research findings indicate that this overall advantage the married have is partly due to selection effects, with the healthier being more likely to be chosen as marriage partners (e.g., Soons \& Kalmijn, 2009). On the other hand, marriage itself may also have a more powerful effect on mental health than cohabitation, either as a mechanism of social control or commitment, or by providing spouses with a deeper sense of meaning, belonging, and purpose in life (Bierman et al., 2006; Marcussen, 2005; Soons \& Kalmijn, 2009).

A study by Fokkema (2001) reveals that finding a new partner after divorce is probably the most effective coping strategy, because the new partner brings in an additional wage and thus adds to financial security, which contributes to well-being. This is especially important for women as they are often economically less well off after divorce. However, what the effect of this new relationship is in addition to its financial aspect, and how the quality of this relationship influences the well-being of both divorced men and women, is still relatively unknown. The literature also fails to adequately examine whether a remarriage after a divorce (also) has an advantage over post-divorce cohabitation. Therefore, to prove or disprove for a "marriage effect" over and above a "partner effect" in new post-divorce relationships, this study differentiates between new cohabiting partnerships and new marital relationships. We also question whether the impact of conflict on mental health differs between these new marriages and post-divorce cohabiting relationships. As prior research has found that cohabiting relationships are in general characterized by lower levels of commitment (Marcussen, 2005), we expect to find that problems and conflict in these relationships are more often experienced as existential, creating more stress and putting more of a strain on mental health. 
Obviously, divorcees have a relationship history and people divorce for a variety of reasons and experience different levels of discontent in marriage. As such, conflict or prior marital quality is likely to be an important pre-divorce characteristic moderating the link between divorce and mental health. According to psychological theories that underscore the long-term impact of chronic stress, long-term, low-quality relationships characterized by conflict often leave lasting marks on a person's identity, self-esteem, and ability to cope (Umberson, Williams, Powers, Liu, \& Needham, 2006). Consequently, prior marital strain may damage mental health long after the marriage has ended. This suggests that divorcees who indicate that there was a lot of conflict in their marriage will report worse mental health than divorcees who experienced a less conflict-loaded marriage. Alternatively, Kalmijn and Monden's escape hypothesis (2006) states that a divorce can be seen as an escape from a negative situation, facilitating positive changes. According to this hypothesis, divorcees who had a prior marriage of low quality, characterized by high levels of conflict, will feel more relieved after separation, and thus report better mental health than those divorcees whose marriages were of relatively good quality with low levels of conflict. Studies by Booth and Amato (1991) and by Amato and Hohmann-Marriott (2007) confirmed that people who reported many problems during marriage tended to be relatively better off after divorce. Theories of loss and grief resolution (DeGarmo \& Kitson, 1996; Prigerson et al., 1999) support this idea and state that divorcees who rate the quality of their prior marriage as high will have worse mental health, because they may lose more than they gain from divorce. Nevertheless, studies by Williams (2003) and Kalmijn and Monden (2006) found only limited evidence to support this: Low levels of quality in a prior marriage lead to increases in depressive symptoms after divorce, although these increases were indeed smaller than the decreases found at higher levels of prior marital quality. 
In addition to new partner relationships and prior marital conflict, the quality of the current relationship with the ex-spouse is also worth studying with regard to post-divorce adjustment, because problematic relationships between ex-spouses can be expected to relate to worse mental health, as hostile relationships — especially with significant othersnegatively impact feelings of well-being (Fincham \& Beach, 1999). Masheter (1997) found that in addition to quarrelling, preoccupation with the ex-spouse is also associated with lower well-being, meaning that having no more contact with one's ex-spouse, regardless of the quality of this contact, might be even more beneficial as it facilitates closure and the making of a new start. In the late seventies, the dominant idea was that ongoing relationships and involvement between ex-partners is pathological, drains emotional and physical energies, and prevents people from forming new relationships and moving on (Ahrons, 2007). Currently, in Belgium as well as in other European countries, legal reforms regarding post-divorce child custody issues seem to reflect a totally different perspective: Co-parenting (with a 50/50 custody arrangement) has been the norm in Belgium since 2006, which forces ex-partners to co-operate and share decision making across a wide variety of life domains. In addition, breaking contact between ex-partners with a classical custody arrangement (week/weekend arrangement) is considered neither easy, nor ideal.

\section{Gender, Conflict and Mental Health}

According to gender role theories, men particularly value power and autonomy, whereas women put involvement and commitment more at the core of their identity (Bracke, 1998, 2000; Courtenay, 2000; Kalmijn \& Monden, 2006; McBride, Bacchiochi, \& Bagby, 2005; Rosenthal, 1985). Therefore, conflict is expected to affect women more than men, especially if it involves significant others, like a partner. In their 2004 study, Williams and Umberson (as cited in Carr \& Springer, 2010) confirmed that effects of (marital) strain are generally stronger for women. Similarly to partner relationships, we expect also the quality of 
the current relationship with the ex-spouse to relate more strongly to the well-being of women. Furthermore, according to the rumination theory of depression (McBride \& Bagby, 2006; Nolen-Hoeksema, 1991, 2012), women reflect on problems and conflict more often than men do. By doing so, however, negative past experiences often remain current problems, having an impact on mental health long after their actual occurrence. Therefore, previously encountered marital problems and conflict can also be expected to affect the well-being of women more than the well-being of men.

\section{The Multiple Dimensions of Mental Health}

In literature, there is one major discourse on mental health that focuses on internalizing versus externalizing indicators of mental health problems. The argument is that both types of indicators should be considered, as there is ample research that finds that men and women respond differently to stress and problems: women seem to internalize stressthis is marked by increased levels of depression, stress, and anxiety—while men seem to express stress externally, through behaviors such as alcohol and substance use (Bierman et al., 2006; Larson \& Grayson, 1999; McBride et al., 2005; Nolen-Hoeksema, 2012; Piccinelli \& Wilkinson, 2000; Simon, 2002; Van de Velde, Bracke, \& Levecque, 2010).

However, a more recent discourse in mental health literature focuses on negative versus positive mental health, on distress or mental ill health versus well-being (e.g., Payton, 2009), rather than on externalized versus internalized indicators. In most research, distress, which can be defined as the experience of emotional suffering, is studied (Mirowsky, 2007). It is mostly measured using indicators of psychological and emotional upset as depression and anxiety. The studies that focus on positive mental health or subjective well-being often use broad indicators, such as happiness and life satisfaction (hedonic well-being); more recently they also use dimensions that reflect positive functioning, such as mastery and selfesteem (eudemonic well-being; Keyes, 2002, 2005; Ryan \& Deci, 2001; Ryff, 1989; Ryff \& 
Singer, 1998). Because distress and positive mental health only moderately correlate (around -.50; Bradburn, 1969; Payton, 2009), it cannot be assumed that what holds true for one inversely holds for the other. This points out an important criticism of classical social stress research: that it too often claims to study mental health when focusing only on emotional distress or mental health problems (Bracke, 1993, 2001; Cacioppo \& Berntson as cited in Ryan \& Deci, 2001; Ryff \& Keyes, 1995; Wheaton, 1990). Moreover, indicators of distress and well-being may well be influenced by different conditions, making it even more interesting to study both (Payton, 2009; Bierman et al., 2006).

The extent to which indicators of positive functioning also relate to gender is not yet clear, nor is whether prior marital conflict and conflict in current relationships is more likely to affect negative versus positive mental health after divorce, and whether this effect differs between men and women. In order to fill this void, this study focuses on a wide array of internal indicators of mental health: depression as an indicator of distress, life satisfaction as a general indicator of well-being, and self-esteem and mastery as indicators of positive functioning. Self-esteem refers to the extent to which people hold themselves in high or low regard (Seff, Gecas, \& Ray, 1992, p. 574), and mastery refers to the sense of personal control (Mirowsky \& Ross 1989; Ross \& Mirowsky, 2002). Both are important determinants of effective behavior in daily life and allow us to deviate from seeing divorce as a negative event which people passively undergo (Thoits, 1994), and to pursue a more active discourse focusing on possibilities rather than risks.

\section{Research Questions and Hypotheses}

As we untangle the relationship between divorce, conflict, and mental health, we consider whether prior marital conflict is still associated with mental health scores among divorcees in the present, how conflict in current relationships with a new partner and with the ex-partner is related to mental health, and whether remarriage is more beneficial than a 
cohabiting relationship after divorce. Furthermore, we question whether prior and/or current conflict relates (differently) to the mental health outcomes of men versus women.

We hypothesize (1) that being in a new intimate relationship after divorce is positive for mental health and that remarriage has an advantage over cohabitation;(2) that conflict in post-divorce relationships relates to worse mental health, especially when it has to do with conflict in cohabiting relationships; and (3) that conflict with the ex-partner also relates to higher levels of depression and lower levels of positive mental health. Concerning the impact of prior marital conflict we hypothesize (4a) that more conflict in the prior marriage relates to higher levels of depression and lower levels of positive functioning (cf. chronic impact of conflict). Alternatively, we hypothesize (4b) that higher levels of prior marital conflict relate to better mental health afterwards (cf. escape hypothesis and theories of loss and grief resolution). Overall, (5) we expect the relation between conflict and mental health to be more pronounced in women (cf. gender role theory and theories of rumination).

\section{Methods}

\section{Data and Participants}

We use data from the DIF, or Divorce in Flanders, survey (Mortelmans et. al., 2011). The sample of this survey is based on a selection of heterogamous marriages (some of which currently ex-marriages) taken from the Public Register. All included marriages were legally formed between 1971 and 2008 in Flanders. The selection criteria were that both partners (or currently ex-partners) had to be Belgian nationals since birth and that both are currently domiciled in Flanders. To ensure that we captured a diverse population of divorcees, broken marriages were oversampled (2/3) compared to still intact marriages (1/3). With regard to the broken marriages, only first divorces were included, which means that respondents could have married twice, but divorced only once. In the survey, the currently married are as such either part of the continuously married (or the "never divorced"; not included in the present 
study) or part of those who remarried after divorce. Data was gathered from 6,470 married and divorced people in Flanders, between 21 and 83 years of age. Both partners (or current ex-partners) were contacted individually for their participation. Respondents were questioned in 2009-2010 using a computer-assisted personal interview (CAPI).

For purposes of this study, we selected respondents between 25 and 60 years of age who divorced a maximum of 10 years prior to the survey. We excluded those divorced more than 10 years prior to the survey because they are more at risk of retrospective bias. Men and women who divorced less than one year prior to participating were also excluded, as their answers on the measures of conflict with the ex-spouse currently and prior to divorce would confound the timeline (cf. infra). Furthermore, only divorcees whose ex-partner also participated were included, because our estimate of prior marital conflict and current conflict between ex-partners requires the scores of both partners (cf. infra). The individual response rate among the divorced was $43.4 \%$, and out of the divorced couples that were initially selected, $21.1 \%$ included participation by both ex-spouses. The sample included 910 respondents (455 men and 455 women). Not all divorcees in the sample had repartnered: 55\% of men and $46 \%$ of women had. For repartnered respondents who had a missing on the question about conflict with this new partner (35 cases), missing values were substituted by the mean, making it possible to use all other valid information offered by them on the remaining variables. By using mean substitution, we avoided a further reduction of the sample, without influencing the effects of conflict in current relationships. Furthermore, we had three respondents with a missing value for prior marital conflict, and six for conflict in the current ex-partner relationships. Because the scores of both ex-partners on these variables were however necessary for creating the combined, more objective measures, we had to omit these nine couples from the sample. The final sample therefore consists of 446 ex-couples (see Figure 1).We did not select triads (both ex-partners plus the new partner(s) 
participating), because after imposing the conditions of both ex-partners' participation (a dyad) and the presence of a new partner, only $64 \%$ of women's new partners and $74 \%$ of men's new partners participated in the survey. Though this response rate is quite good, the amount it would further reduce the total sample size of this study would be problematic.

Figure 1. Selection of the sample, data inclusions and exclusions (DIF, 2009-2010)

\section{Indicators of Mental Health}

Depression is measured using an 8-item version of the Center for Epidemiologic Studies Depression Scale (CES-D; Radloff, 1977). The CES-D was constructed to identify populations at risk of developing depressive disorders. However, it should not be used as a clinical diagnostic tool by itself (Radloff, 1977). Respondents were asked to indicate how often in the week before the survey they felt or behaved in a certain way (felt depressed, felt that everything was an effort, slept badly, felt lonely, felt sad, could not get going, enjoyed life, or felt happy). Response categories range from none or almost none of the time (score = 0) to all or almost or all of the time (score $=3$ ). We assessed scale scores for the CES-D 8 using non-weighted, summated rating. Scores range from 0 to 24 , with higher scores indicating a greater frequency and severity of depressive complaints. Reliability and validity are confirmed across gender and countries (Van de Velde et al., 2010). Cronbach's alpha is estimated at 0.86 .

Self-esteem is measured using the Rosenberg self-esteem scale (Rosenberg, 1965). Respondents were asked to what extent they agreed or disagreed with 10 items, such as "I am able to do things as well as most other people," "I take a positive attitude toward myself," and “All in all I think I am a failure." Answers vary from 1 (totally disagree) to 5 (totally agree). The scale shows good reliability (Cronbach's alpha $=0.87$ ). Scores range from 0 to 40 .

Mastery is measured using Pearlin's 7-item mastery scale (Pearlin et al., 1981). Respondents were asked whether they agreed or disagreed with statements, such as "There is 
little I can do to change important things in my life," "I often feel helpless in dealing with the problems of life," and "What happens to me in the future depends for the biggest part on myself." Answers vary from 1 (totally disagree) to 5 (totally agree). The scale shows good reliability (Cronbach's alpha $=0.81)$. Scores range from 0 to 28 .

Life satisfaction was chosen as a general indicator of mental health and is measured using the question "How satisfied or dissatisfied are you with your life as a whole nowadays?" This question was taken from the European Social Survey (2006; cf. Diener's life satisfaction scale). Answers range from 0 (extremely dissatisfied) to 10 (extremely satisfied).

\section{Partner Status}

Respondents in the sample are all divorced, but may differ with regard to their current partner status. Three dummies were created: the single (reference category); the remarried; and those cohabiting with a new partner. The cohabiting are couples who live in the same household as partners without being married.

\section{Indicators of Conflict}

For all measures of conflict (prior marital conflict, current conflict with the ex-partner, and conflict with the new partner) a similar measure is used that was extracted from the question, "How often has the following situation occurred between you and your ex-partner in the year before you started living separately?": We "blame each other"; "yell or scream"; "use physical violence"; "throw or break things deliberately"; and "do not want to talk to each other for a while." We used the same question for the measures on current conflict with the ex-partner and with the new spouse or new cohabiting partner during the past 12 months. Response scores vary from 1 (never) to 7 (daily).

For prior marital conflict and current conflict with the ex-spouse, average scores are calculated based on the scores of both ex-partners $\left(\mathrm{R}_{\text {men-women marital conflict }}=.255^{* *} ; \mathrm{R}_{\text {men-women }}\right.$ 
current conflict $\left.=.310^{* *}\right)$. By doing this, we offer a more objective measure that is less subject to the respondent's well-being and to retrospective bias in the case of prior marital conflict. Scores range from 0 to 30 . The indicator of current conflict with the ex-spouse controls for whether ex-partners are still in contact with each other. Those who are no longer in contact with their ex-spouse score 0 for the conflict measure. Similarly, all analyses control for whether the respondent currently lives with a new spouse or new cohabiting partner.

\section{Control Variables}

The following controls are added as they are found to be important predictors of mental health and confounders in the relationship between divorce and mental health: age of the respondent, minor children (defined as children under the age of 18; children under 18 have compulsory school attendance and their parents remain legally responsible for them) shared with the ex-spouse (yes-no), highest level of education attained (three categories: $1=$ lower secondary education or less; 2 = higher secondary education or post-secondary nonhigher education; 3 = higher non-academic or academic education [reference category]), and household income (EHI; calculated using the Equivalent Income OECD modified scale (Haagenars, de Vos, \& Zaidi, 1994). This scale includes five categories: those having less than $50 \%$ of the mean equivalent household income (MEHI; 1); those having between $50 \%$ and $79 \%$ of MEHI (2); those having between $80 \%$ and $119 \%$ of MEHI (3; reference category); those having more than $120 \%$ of the MEHI (4); and those offering no information about their income (5). This OECD scale controls for the number of people living in the household and gives different weighting to adults $(* 0.5)$ and minor children $(* 0.3)$. Moreover, our data also allowed us to consider alimony (i.e., financial support transferred between ex-spouses either for themselves or on behalf of their joint children), with regard to both incomes and expenses. Finally, the time since divorce is measured by the years passed between the date of the actual separation and the date of the interview. A dummy is created to 
make a distinction between those only recently divorced (less than three years prior to the survey), and those divorced for a longer time (reference category). Three years was taken as the cut-off, because research confirming the stress hypothesis has found that mental health levels, on average, regain their initial levels two to three years after divorce (Booth \& Amato, 1991; Kitson, 1992; Lorenz et al., as cited in Amato, 2000).

\section{Analyses}

For all dimensions of mental health (depression, self-esteem, mastery, and life satisfaction), differences in current mental health are studied within the divorced group, using separate linear regression models for all mental health indicators. These include the controls, the indicators for prior marital conflict and current conflict with the ex-spouse, and the indicators for current conflict with the new partner (considered separately for married vs. cohabiting). All analyses are done using multilevel mixed models in PASW 18.0. Multilevel mixed models were used because the assumption of independency of observations is violated by the coupled nature of the data: respondents are clustered in ex-households. After adding the individual- and household-level variables to the baseline model, the interaction terms of the core variables with gender were added one by one to the model. The final model (represented in Table 2) contains only the estimates of the significant interaction terms. Whereas this model contrasts single divorcees with those living together with a new spouse or cohabiting partner, additional analyses contrast the remarried with the single and the cohabiting in order to test for the existence of a marriage effect/cohabitation gap with regard to post-divorce relationships (not in table).

\section{Results}

\section{Descriptive Results}

The mean age of the respondents in our sample is 42 for women and 44 for men. For all indicators of mental health except life satisfaction, women score on average worse than 
men do. They report more symptoms of depression and slightly less self-esteem and mastery, (Table 1). With regard to the measure for prior marital conflict, men and women rate quite differently, with women reporting more conflict $\left(M_{\text {women }}=9.56\right.$ [s.d. 6.39] vs. $M_{\text {men }}=7.91$ [s.d. 5.41], $\mathrm{p}<.001)$. In contrast, mean scores of men and women do not differ with regard to the level of conflict in the current relationship with the ex-partner. Though $80 \%$ of the divorcees are still in contact with their ex-spouse, overall they indicate little conflict. Concerning post-divorce relationships, $46 \%$ of the divorced women and $55 \%$ of men currently live with a new partner. Approximately $34 \%$ of these men and women have married their new partner. Self-reported levels of conflict do not differ significantly between those in a new marital relationship and those in a new cohabiting relationship, for either men or women $\left(\mathrm{t}_{\mathrm{men}}=-1.431, \mathrm{p}>.05 ; \mathrm{t}_{\mathrm{women}}=1.595, \mathrm{p}>.05\right)$, nor do perceptions of conflict in these post-divorce relationships differ between men and women (Table 1).

Further, while in our sample approximately as many women as men are in paid labor, and women are more often high educated, descriptive results indicate that women are at the same time more at risk of poverty: Whereas only $32 \%$ of divorced men have less than $79 \%$ of the mean equivalent household income, $43.5 \%$ of divorced women have. This might partly be because children more often reside with their mothers, either in sole custody (22.4\%), or in co-residence (weekend or week-to-week arrangement, 70\%; not in table). Approximately $62 \%$ of the couples in our sample have shared minor children, $39.5 \%$ have shared adult children, and $15 \%$ have no shared children (not in table). Finally, approximately $14 \%$ of the couples divorced less than three years prior to the survey. The $1.5 \%$ score difference between men and women is due to retrospective bias on remembering dates.

Table 1. Descriptive Statistics of Male and Female Respondents, Divorce in Flanders 2009$2010(N=892)$

\section{Conflict and Mental Health}


In line with prior research, our results indicate that being in an intimate relationship is beneficial to well-being (Table 2). After controlling for all other factors, our findings show that divorcees with a new partner are in general less depressed, report higher levels of selfesteem, and are more satisfied with life than divorcees without a new partner. This holds for both men and women, irrespective of whether the divorcee is married to the new partner or not. Divorcees who are not married to their new partner also report higher levels of mastery than single divorcees. Additional analyses comparing the remarried with the single and the cohabiting showed — controlling for all other variables—no additional mental health differences between those in a marital versus a non-marital post-divorce relationship. Parameter estimates were even significantly higher for the cohabiting compared to the married for feelings of mastery $(\mathrm{B}=1.75$ [SE $=0.64], \mathrm{p}<.01$, not shown). So overall, for both men and women, a new partner after divorce significantly relates to better mental health. However, when this relationship is characterized by conflict, a substantial part of its advantage is lost. Interestingly, the impact of conflict on mental health does seem to depend on the type of relationship: While conflict in new marital relationships relates only to higher levels of depression and to lower levels of life satisfaction, conflict in new cohabiting relationships relates also to lower levels of self-esteem and mastery. Moreover, for women, parameter estimates of conflict in new cohabiting relationships for depression and life satisfaction are around two times as high as those of conflict in new marital relationships, though this is not the case for men (Table 2; depression: $\mathrm{B}_{\text {cohabiting, men }}=.438[.703-.265] \mathrm{vs}$. $\mathrm{B}_{\text {married, men }}=.281$; life satisfaction: $\mathrm{B}_{\text {cohabiting, men }}=-.165[-.304+.139]$ vs. $\mathrm{B}_{\text {married, men }}=-$ .189). Interaction terms of gender with conflict in new cohabiting relationships are significant for all mental health outcomes except mastery. This indicates an overall gender-differential impact of conflict in non-marital post-divorce relationships, with women suffering more from conflict in these relationships than men. 
Despite the overall negative effect of conflict in intimate relationships, predicted means reveal that those women and men who report many conflicts in their new relationship $(+2$ s.d. above the mean) would in general still be better off than single divorcees, all other conditions set equal. It is clear, especially with regard to depressive feelings and life satisfaction, that both the remarried and cohabiting have overall better mental health reports, even when confronted with many conflicts in these post-divorce relationships. These findings are illustrated in Figures 2 and 3 for feelings of depression and life satisfaction. Results regarding self-esteem and mastery follow the same pattern, but are less pronounced (not shown). Figure 2 also highlights the differential impact of conflict on feelings of depression and life satisfaction in women in cohabitation versus remarriage.

Figure 2. Estimated means for feelings of depression and life satisfaction of single divorced women versus women in a high conflict-loaded (+2 s.d.) new partner relationship, all else set equal (DIF, 2009-2010) ${ }^{1}$

Figure 3. Estimated means for feelings of depression and life satisfaction of single divorced men versus men in a high conflict-loaded (+2 s.d.) new partner relationship, all else set equal (DIF, 2009-2010) $)^{2}$

Concerning the ex-partner, analyses reveal that continuing to have contact after divorce is not inherently positive or negative regarding mental health. Stressful post-divorce relationships however do damage both men and women's well-being: higher levels of conflict with the ex-spouse relate to more feelings of depression and to lower levels of mastery in both men and women (Table 2).

\footnotetext{
${ }^{1}$ Estimated means are calculated using parameter estimates of gender-separate analyses (not shown), using following parameters: mean age, having continued contact with the ex-spouse, mean levels of conflict with the ex-spouse now and mean levels of conflict with regard to prior marital conflict.

${ }^{2}$ Estimated means are calculated using parameter estimates of gender-separate analyses (not shown), using following parameters: mean age, having continued contact with the ex-spouse, mean levels of conflict with the ex-spouse now and mean levels of conflict with regard to prior marital conflict.
} 
Analysis of the correlation between the indicators for conflict with the new partner and current conflict with the ex-partner show no significant results $\left(\mathrm{R}_{\mathrm{men}}=.081, \mathrm{p}>.05\right.$; $\mathrm{R}_{\text {women }}=.073, \mathrm{p}>.05$, not shown). This indicates that high conflict levels (with either the expartner or the new partner) stem from problematic relationships rather than from respondents who have a tendency to attract conflict or to problematize small issues and disputes in relationships.

In contrast to the above-mentioned indicators of conflict, prior marital conflict does not seem to relate to lower well-being in either divorced men or women. To the contrary, results cautiously indicate that the more the prior marriage was characterized by conflict, the more satisfied respondents are with their current life.

Further, the results for level of education, work status, and income confirm that having a job and educational level is positively related to well-being. The risk of poverty (having less than $50 \%$ or $79 \%$ of the MEHI) also relates to lower well-being. Surprisingly, no mental health difference was found between those who only recently divorced versus those who divorced more than three years age. There was also no significant difference found between those with and those without shared minor children. The latter may be a result of the competing impacts of support versus strain inherent to having children.

Table 2. The Mental Health of Divorced Men and Women and Conflicts with New Partner and Ex-partner (DIF, 2009-2010)

\section{Discussion}

Because this study employed a contextual approach, we did not view divorce as something inherently stressful, but rather as something whose impact depends on a variety of life conditions. The intimate relationships of divorcees and the way in which conflicts in these relationships relate to mental health are central to this study. In addition to conflict in new partner relationships, conflict with the ex-partner and conflict during the prior marriage 
are also considered. Using a divorce-specialized dataset (www.divorceinflanders.be), we chose a multidimensional operationalization of mental health that incorporates both negative and positive mental health indicators: feelings of depression, self-esteem, mastery, and life satisfaction. We used data from 892 respondents (446 men and 446 women), with a special focus on gender and gender-differential effects.

\section{Limitations}

Before discussing the main findings, some limitations are worth noting to avoid any misinterpretation of the data. First, the present study is based on cross-sectional data. Because of the shortage of longitudinal data, one should be careful in drawing causal conclusions. Some selection effects remain possible over and above supposed causations. So interpreting the results in terms of impact of conflict could result in an overestimation, as those in poor mental health are also less likely to build warm or committed relationships with others. Longitudinal data is necessary to estimate to what extent this overestimation is or is not significant.

On the other hand, both ill mental health and the occurrence of conflict are likely underestimated in the survey as people who are worse off are less likely to participate (cf. the interviewers indicated that it was their perception that for approximately $60 \%$ of (ex)partners, the refusal to participate was linked to the topics under study in the survey (too private, too difficult, etc.). Therefore, the fact that ex-spouses indicate little conflict overall in their current relations could be, in part, due to sample bias.

Third, although approximately 1 in 10 divorces in Flanders today is a second divorce, only first divorces are included in the study. Although comparing first and second divorces with regard to mental health would be interesting, it falls outside of the scope of this research and data opportunities. 
Fourth, the measure of prior marital conflict is based on retrospective questioning. This means that answers may be biased either because of the time that has passed since the divorce or because of the quality of the current relationship with the ex-partner. Nevertheless, by including only ex-partners whose ex-spouse also participated in the survey, we were able to create more objective measures of conflict, based on the assessment of both ex-partners, for both prior marital conflict and current conflict between ex-spouses.

\section{Findings}

First, in line with hypothesis 1, we find that for both men and women, having a new partner seems to make a big difference for mental health after divorce: Compared to single divorcees, men and women who live together with a new partner are significantly more satisfied with life, report higher levels of self-esteem and mastery, and feel less depressed. This holds for both the cohabiting and the married (excl. mastery) and also holds true after controlling for financial situation; thus, it seems that partner relationships, despite their increasing instability, currently remain at the core of men and women's identity. This positive effect is seen even in relationships characterized by high conflict ( 2 s.d. above the mean). Additional analyses found no proof of the existence of a marriage effect or cohabitation gap in new post-divorce relations: The remarried did not score significantly better than the cohabiting for any indicator of mental health. To the contrary, the cohabiting reported even higher levels of mastery than the married, and this finding could not be linked to differences in the duration of the relationships. Because these respondents had already experienced a divorce, it is possible that some felt a greater need for freedom and self-control, and those respondents therefore chose not to marry again. However, it should be noted that a substantial number of the currently cohabiting eventually will marry again. Therefore future research should continue to explore alternative explanatory factors. 
Second, regarding conflict, results reveal that conflicts in new partner relationships, as well as conflicts in the current relationship with the ex-partner, are related to worse mental health for both men and women, which gives support to our second hypothesis. However, in contrast to what was hypothesized, conflict in intimate relationships seems to have a similar impact on men and women's mental health. This is shown by the fact that almost no interaction term with gender was significant. This is in contrast to gender role theory and rumination theories, but is in line with the 1996 study by Umberson et al. that found that, overall, men and women experience similar levels of distress related to relationship quality. Although their study focused on a wide array of relationships (partner, family, friends, etc.) and not solely on relationships between (ex-)partners, their findings in combination with ours may be an indication that men and women are less different than often thought. Nevertheless, one important gender-differential effect remained apparent: Conflicts in post-divorce partner relationships seem to have a worse impact women's mental health than men's, though only when it concerns non-marital relationships. This may suggest that the (emotional) benefits of marriage may be felt more by women in case of conflict, as they are, more than men, sensitive to the quality of intimate relationships and to the insecurity related to conflict in cohabiting relationships. Other studies also find that women's well-being is more influenced by the presence of conflict and lack of relationship commitment (Kiecolt-Glaser \& Newton, 2001; Rosenthal, 1985). Therefore, relationship counseling might pay off for both men and women's mental health, though it might benefit women slightly more. This gendered "emotional benefit of marriage," which women benefit more from, somewhat contrasts with, or rather complements, other research that mentions a marriage benefit for men over women (Aneshensel, Rutter, \& Lachenbruch, 1991; Gove, 1972; Gove \& Tudor, 1973; Menaghan, 1989) or that finds that marriage benefits men and women equally (Simon, 2002). It contrasts with the findings of Simon and Barrett (2010) that support and strain in an ongoing 
relationship are more closely related to men's emotional well-being. However, although many studies continue to contrast the married with the divorced or the never married, more research is needed on the differences between the married and the cohabiting, especially in post-divorce relationships.

Third, although the low average score on conflict with the ex-spouse seems to indicate that in most cases conflict levels with the ex-partner fall dramatically after divorce, postdivorce relationships between ex-partners rated as conflict loaded still relate to worse mental health for both men and women, as expected.

Fourth, results indicate that the negative impact of conflict seems to be only temporary as prior marital conflict does not relate to lower well-being in the present, either for women or for men. In contrast, to our surprise the findings show reversed results: The more conflict characterized a prior marriage, the more satisfied divorcees feel with their current life. This finding is contrary to what we expected based on theories underlining the chronic impact of conflict (hypothesis 3a), but is in line with hypothesis $3 \mathrm{~b}$, pointing to the escape hypothesis and the idea of relief. This finding, and the above-mentioned results, illustrates the duality in the impact of conflict and the importance of using a contextual approach and looking at different dimensions of mental health as well as possible genderdifferential effects.

\section{Future Directions}

In addition to the suggestions for further study given above, future research could dig deeper into the topic of conflict in post-divorce relationships. First, more contextual factors linked to mental health and post-divorce relationship quality should be considered. Concerning the quality of the relationship between ex-spouses, research on the effect of initiation in divorce could also prove worth pursuing. Previous research has found that more women than men file for divorce (Centraal bureau voor de statistiek, 2009; Hewitt, 2009; 
Kalmijn \& Poortman, 2006; Mortelmans, 2008); it has also found that those who took the initiative in divorce, whether women or men, tend to be better adjusted and to fare better emotionally in the post-divorce period (Amato, 2000; Kitson, 1992; Wang \& Amato, 2000). This is also true in cases of jointly initiated separations (Hewitt \& Turrell, 2011). A next question is whether joint initiation also relates to better post-divorce relationships between ex-spouses. For men especially, divorce-counseling therapy aimed at helping them gain insight into problems in a prior marriage and the necessity of divorce might pay off, not only for their well-being but also for the "health" of post-divorce relationships with their exspouses. Further research into this would be interesting.

Second, as mentioned above, a substantial proportion of the cohabiting will eventually remarry, while some will remain cohabiting. Future research could investigate whether there are significant differences between these two groups, for it is possible that the first group already has more characteristics in common with the married, while the second group may share more characteristics with the single. Third, prior research has revealed that women are more inclined to express feelings of stress verbally, while men express stress in more indirect ways, such as alcohol consumption and anti-social behavior (Aneshensel et al., 1991; Baum, 2003; Nolen-Hoeksema, 2012; Nolen-Hoeksema, Larson \& Grayson, 1999). Future research considering other outcomes, such as problem behavior and alcohol use, could elaborate further on gender differences in dealing with conflict, divorce, and well-being. And fourth, research on the impact of conflict on the well-being of children after divorce is needed as well, as "for the sake of the children" is an often-heard reason to temper conflict between exspouses and to put aside personal rancor.

\section{References}

Ahrons, C. R. (2007). Introduction to the special issue on divorce and its aftermath. Family Process, 46(1), 3-6. 
Amato, P. R. (2000). The consequences of divorce for adults and children. Journal of Marriage and Family, 62, 1269-1287.

Amato, P. R., \& Hohmann-Marriott, B. (2007). A comparison of high- and low-distress marriages that end in divorce. Journal of Marriage and Family, 69, 621-638.

Aneshensel, C. S. (1992). Social stress: Theory and research. Annual Review of Sociology, $18,15-38$.

Aneshensel, C. S., Rutter, C. M., \& Lachenbruch, P. A. (1991). Social structure, stress, and mental health: Competing conceptual and analytic models. American Sociological Review, 56(2), 166-178.

Aseltine, R. H., \& Kessler, R. C. (1993). Marital disruption and depression in a community sample. Journal of Health and Social Behavior, 34, 237-251.

Baum, N. (2003). The male way of mourning divorce: When, what, and how. Clinical Social Work Journal, 31(1), 37-50.

Bierman, A., Fazio, E. M., \& Milkie, M. A. (2006). A multifaceted approach to the mental health advantage of the married: Assessing how explanations vary by outcome measure and unmarried group. Journal of Family Issues, 27(4), 445-582.

Booth, A., \& Amato, P. R. (1991). Divorce and psychological stress. Journal of Health and Social Behavior, 32, 396-407.

Bracke, P. (1993). Geslachtsverschillen in mentale gezondheid. Enkele kritische bedenkingen omtrent het gebruik van het sociale stress model [Gender differences in mental health. Some critical reflections on the use of the social stress model]. Tijdschrift voor Sociologie, 14(2), 223-245.

Bracke, P. (1998). Depressiviteit en de economische gevolgen van echtscheiding voor vrouwen en mannen [Depression and the economic consequences of divorce for women and men]. Mens en Maatschappij, 73(3), 239-258. 
Bracke, P. (2000). Over macht en depressiviteit: Een sociaal-relationele visie [On power and depression: A social-relational perspective]. Tijdschrift voor Sociologie, 21(1), 5-30.

Brown, S. L. (2000). The effect of union type on psychological well-being: Depression among cohabitors versus marrieds. Journal of Health and Social Behavior, 41(3), $241-255$.

Carr, D., \& Springer, K. W. (2010). Advances in families and health research in the $21 \mathrm{st}$ Century. Journal of Marriage and Family, 72, 743-761.

Centraal Bureau voor de Statistiek (2009). Relatie en gezin aan het begin van de $21^{\mathrm{e}}$ eeuw. Den Haag: Centraal Bureau voor de Statistiek.

Choi, H., \& Marks, N. F. (2008). Marital conflict, depressive symptoms, and functional impairment. Journal of Marriage and Family, 70, 377-390.

Courtenay, W. H. (2000). Constructions of masculinity and their influence on men's wellbeing: A theory of gender and health. Social Science and Medicine, 50, 1385-1401.

DeGarmo, D. S., \& Kitson, G. C. (1996). Identity relevance and disruption as predictors of psychological distress for widowed and divorced women. Journal of Marriage and Family, 59(4), 983-997.

Dohrenwend, B. P., \& Dohrenwend, B. S. (1976). Sex-differences and psychiatric disorders. The American Journal of Sociology, 81(6), 1447-1454.

Fincham, F. D., \& Beach, S. R. H. (1999). Conflict in marriage: Implications for working with couples. Annual Review of Psychology, 50(1), 47-77.

Fokkema, T. (2001). Forse inkomensdaling voor vrouwen na echtscheiding en vroege verweduwing: Bieden hertrouw en werk uitkomst? [Remarkable decline in income for women after divorce and early widowhood: Do remarriage and work provide a way out?]. Bevolking en Gezin, 30, 5-29. 
Gecas, V. (1989). The social psychology of self-efficacy. Annual Review of Sociology, 15, 291-316.

Haagenars, A., de Vos, K., \& Zaidi, M. A. (1994). Poverty statistics in the late 1980s: Research based on micro-data. Luxembourg: Office for Official Publications of the European Communities.

Hewitt, B. (2009). Which spouse initiates marital separation when there are children involved? Journal of Marriage and Family, 71(2), 362-372.

Hewitt, B., \& Turrell, G. (2011). Short-term functional health and well-being after marital separation: Does initiator status make a difference? American Journal of Epidemiology, 173(11), 1308-1318.

Horwitz, A. V., \& White, H. R. (1998). The relationship of cohabitation and mental health: A study of a young adult cohort. Journal of Marriage and the Family, 60(2), 505-515.

Horwitz, A. V. McLaughlin, J., \& White, H. R. (1997). How the negative and positive aspects of partner relationships affect the mental health of young married people. Journal of Health and Social Behavior, 39, 124-136.

Kalmijn, M. (2010). Country differences in the effects of divorce on well-being: The role of norms, support, and selectivity. European Sociological Review, 26(4), 475-490.

Kalmijn, M., \& Broese Van Groenou, M. I. (2005). Differential effects of divorce on social integration. Journal of Social and Personal Relationships, 22, 455-476.

Kalmijn, M., \& Monden C. (2006). Are there negative effects of divorce on well-being dependent on marital quality? Journal of Marriage and the Family, 68, 1197-1213.

Kalmijn, M., \& Poortman, A. R. (2006). His or her divorce? The gendered nature of divorce and its determinants. European Sociological Review, 22(2), 201-214.

Keyes, C. L. M. (2002). The mental health continuum: From languishing to flourishing in life. Journal of Health and Social Behavior, 43, 207-222. 
Keyes, C. L. M. (2005). Subjective well-being in mental health and human development research worldwide: An introduction. Social Indicators Research, 77, 1-10.

Kim, H. K., \& Mckenry, P. C. (2002). The relationship between marriage and psychological well-being. A longitudinal analysis. Journal of Family Issues, 23, 885-911.

Kitson, G. C. (1992). Portrait of divorce: Adjustment to marital breakdown. New York: Guilford Press.

Kitson, G. C., \& Morgan, L. A. (1990). The multiple consequences of divorce: A decade review [Family Research in the 1980s: The Decade in Review]. Journal of Marriage and Family, 52(4), 913-924.

Li, Q., Wilsnack, R., Wilsnack, S., \& Kristjanson, A. (2010). Cohabitation, gender and alcohol consumption in 19 countries: A multilevel analysis. Substance Use \& Misuse, $45,2481-2502$.

Lucas, R. E. (2005). Time does not heal all wounds. A longitudinal study of reaction and adaptation to divorce. Psychological Science, 16(12), 945-950.

Marcussen, K. (2005). Explaining differences in mental health between married and cohabiting individuals. Social Psychology Quarterly, 68(3), 239-257.

Marks, N. F. (1996). Flying solo at midlife: Gender, marital status, and psychological wellbeing. Journal of Marriage and Family, 58, 917-932.

Marks, N. F., \& Lambert, J. D. (1998). Marital status continuity and change among young and midlife adults. Journal of Family Issues, 19, 652-686.

Masheter, C. (1997). Healthy and unhealthy friendship and hostility between ex-spouses. Journal of Marriage and Family, 59(2), 463-475.

McBride, C., \& Bagby, R. M. (2006). Rumination and interpersonal dependency: Explaining women's vulnerability to depression. Canadian Psychology, 47(3), 184-194. 
McBride, C., Bacchiochi, J. R., \& Bagby, R. M. (2005). Gender differences in the manifestation of sociotropy and autonomy personality traits. Personality and Individual Differences, 38, 129-136.

Mortelmans, D. (2008). Copingstrategieën en beleving van sociaal-economische gevolgen bij gescheiden vaders. In D. Cuypers, D. Mortelmans \& N. Torfs (Eds.), Is echtscheiding werkelijk win for life? (pp. 207-222). Brugge: Die Keure.

Mortelmans, D., Pasteels, I., Van Bavel, J., Bracke, P., Matthijs, K., \& Van Peer, C. (2011). Divorce in Flanders [Data collection and code book]. http://www.divorceinflanders.be

Musick, K., \& Bumpass, L. (2012). Reexamining the case for marriage: Union formation and changes in well-being. Journal of Marriage and Family, 74(1), 1-18.

Nolen-Hoeksema, S. (1991). Responses to depression and their effects on the duration of depressive episodes. Journal of Abnormal Psychology, 100(4), 569-582.

Nolen-Hoeksema, S. (2012). Emotion regulation and psychopathology: The role of gender. Annual Review of Clinical Psychology, 8, 161-187.

Nolen-Hoeksema, S., Larson, J., \& Grayson, C. (1999). Explaining the gender difference in depressive symptoms. Journal of Personality and Social Psychology, 77(5), 10611072.

Payton, A. R. (2009). Mental health, mental illness, and psychological distress: Same continuum or distinct phenomena? Journal of Health and Social Behavior, 50, $213-$ 227.

Pearlin, L. I. (1989). The sociological study of stress. Journal of Health and Social Behavior, 30(3), 241-256.

Pearlin, L. I., Menaghan, E. G., Lieberman, M. A., \& Mullan, J. T. (1981). The stress process. Journal of Health and Social Behavior, 22(4), 337-356. 
Piccinelli, M., \& Wilkinson, G. (2000). Gender differences in depression: Critical review. British Journal of Psychiatry, 177, 486-492.

Prigerson, H. G., Maciejewski, P. K., \& Rosenheck, R. A. (1999). The effects of marital dissolution and marital quality on health and health service use among women. Medical Care, 37(9), 858-873.

Proulx, C. M., Helms, H. M., \& Buehler, C. (2007). Marital quality and personal well-being: A meta-analysis. Journal of Marriage and Family, 69, 576-593.

Radloff, L. S. (1977). The CES-D Scale: A self-report depression scale for research in the general population. Applied Psychological Measurement, 1, 385-401.

Rosenberg, M. (1965). Society and the adolescent self-image. Princeton: Princeton University Press.

Rosenthal, C. J. (1985). Kinkeeping in the familial division of labor. Journal of Marriage and Family, 47(4), 965-974.

Ross, C. E. (1991). Marriage and the sense of control. Journal of Marriage and Family, 53(4), 831-838.

Ross, C. E., \& Mirowsky, J. (2002). Age and the gender gap in the sense of personal control. Social Psychology Quarterly, 65(2), 125-145.

Ryff, C. D. (1989). Happiness is everything, or is it? Explorations on the meaning of psychological well-being. Journal of Personality and Social Psychology, 57, 10691081.

Ryff, C. D., \& Keyes, C. L. M. (1995). The structure of psychological well-being revisited. Journal of Personality and Social Psychology, 69(4), 719-727.

Ryff, C. D., \& Singer, B. (1998). The contours of positive human health. Psychological Inquiry, 9(1), 1-28. 
Seff, M. A., Gecas, V., \& Ray, M. P. (1992). Injury and depression: The mediating effects of self-concept. Sociological Perspectives, 35(4), 573-591.

Shapiro, A. (1996). Explaining psychological distress in a sample of remarried and divorced persons. Journal of Family Issues, 17, 186-203.

Shapiro, A., \& Lambert, J. D. (1999). Longitudinal effects of divorce on the quality of the father-child relationship and on fathers' psychological well-being. Journal of Marriage and Family, 61(2), 397-408.

Simon, R. W. (2002). Revisiting the relationship among gender, marital status, and mental health. The American Journal of Sociology, 107(4), 1065-1096.

Simon, R. W., \& Barrett, A. E. (2010). Nonmarital romantic relationships and mental health in early adulthood: Does the association differ for women and men? Journal of Health and Social Behavior, 51(2), 168-182.

Simon, R. L., \& Marcussen, K. (1999). Marital transitions, marital beliefs and mental health. Journal of Health and Social Behavior, 40, 111-125.

Soons, J. P. M., \& Kalmijn, M. (2009). Is marriage more than cohabitation? Well-being differences in 30 European Countries. Journal of Marriage and Family, 71, 11411157.

Strohschein, L., McDonough, P., Monette, G., \& Shao, Q. (2005). Marital transitions and mental health: Are there gender differences in the short-term effects of marital status change? Social Health and Medicine, 61(11), 2293-2303.

Terhell, E. L., Broese Van Groenou, M. I., \& van Tilburg T. (2007). Network contact changes in early and later postseparation years. Social Networks, 29(1), 11-24.

Terhell, E. L., Broese Van Groenou, M. I., \& van Tilburg, T. (2004). Network dynamics in the long-term period after divorce. Journal of Social and Personal Relationships, 21(6), 719-738. 
Thoits, P. A. (1994). Stressors and problem-solving-The individual as psychological activist. Journal of Health and Social Behavior, 35(2), 143-160.

Turner, R. J., Wheaton, B., \& Lloyd, D. A. (1995). The epidemiology of social stress. American Sociological Review, 60(1), 104-125.

Umberson, D., Chen, D. M., House, J. S., Hopkins, K., \& Slaten, E. (1996). The effect of social relationships on psychological well-being: Are men and women really so different? American Sociological Review, 61(5), 837-857.

Umberson, D., Williams, K., Powers, D. A., Liu, H., \& Needham, B. (2006). You make me sick: Marital quality and health over the life course. Journal of Health and Social Behavior, 47(1), 1-16.

Van de Velde, S., Bracke, P., \& Levecque, K. (2010). Gender differences in depression in 23 European countries. Cross-national variation in the gender gap in depression. Social Science \& Medicine, 71, 305-313.

Wang, H., \& Amato, P. R. (2000). Predictors of divorce adjustment: Stressors, resources and definitions. Journal of Marriage and Family, 62, 655-668.

Wheaton, B. (1980). The sociogenesis of psychological disorder: An attributional theory. Journal of Health and Social Behavior, 21(2), 100-124.

Wheaton, B. (1983). Stress, personal coping resources, and psychiatric symptoms: An investigation of interactive models. Journal of Health and Social Behavior, 24(3), $208-229$.

Wheaton, B. (1990). Life transitions, role histories, and mental health. American Sociological Review, 55, 209-223.

Williams, K. (2003). Has the future of marriage arrived? A contemporary examination of gender, marriage, and psychological well-being. Journal of Health and Social Behavior, 44, 470-487. 
Figure 1. Selection of the sample, data inclusions and exclusions (DIF, 2009-2010)

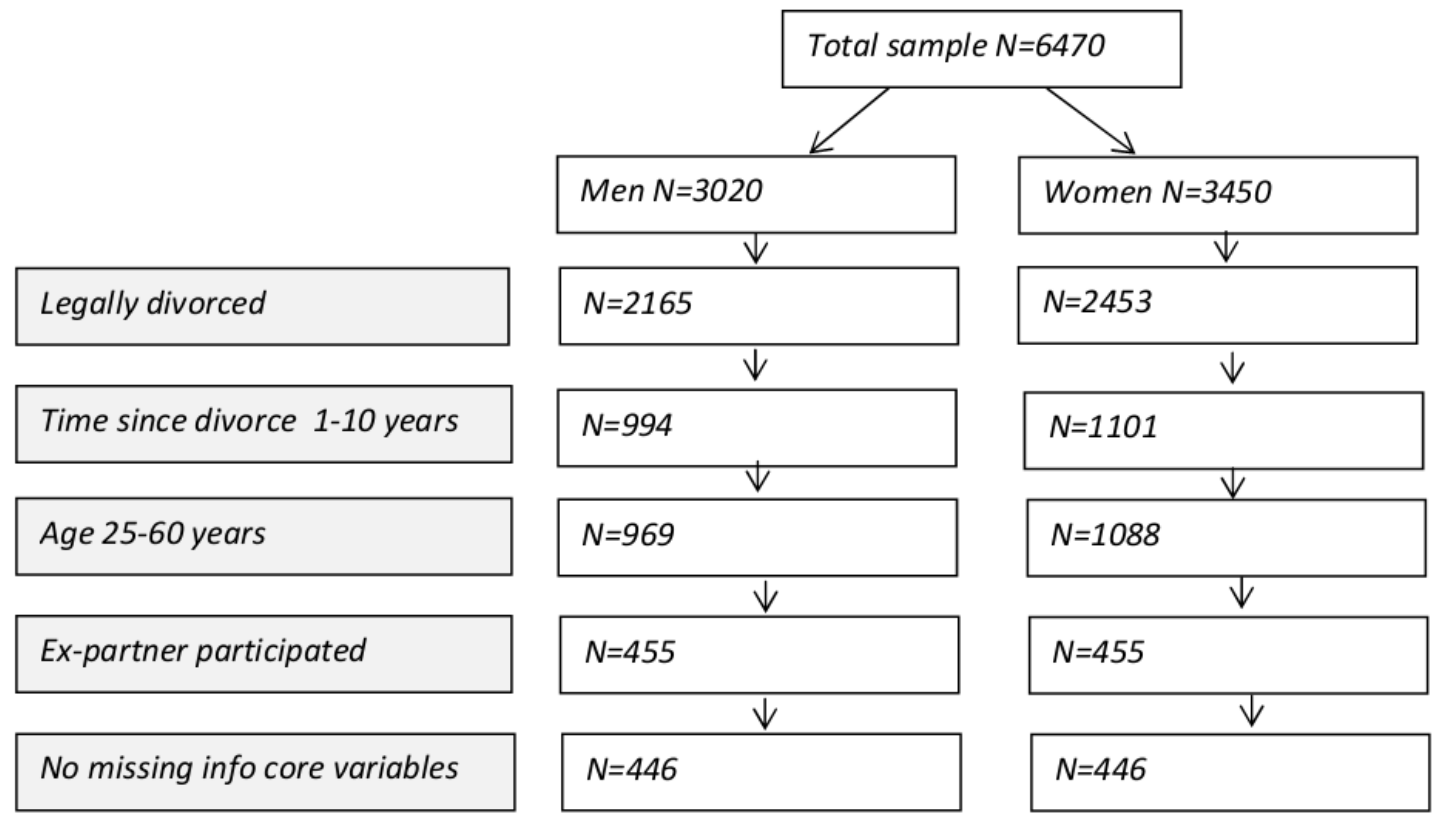


Table 1. Descriptive Statistics of Male and Female Respondents, Divorce in Flanders 2009$2010(N=892)$

\begin{tabular}{|c|c|c|c|c|c|}
\hline \multirow[b]{2}{*}{ Variables } & \multicolumn{2}{|l|}{$\begin{array}{l}\text { Women } \\
(\mathrm{N}=446)\end{array}$} & \multicolumn{3}{|l|}{$\begin{array}{l}\text { Men } \\
(\mathrm{N}=446)\end{array}$} \\
\hline & $\mathrm{M}(\mathrm{SD})$ & $\%$ & $\mathrm{M}(\mathrm{SD})$ & $\%$ & sig. \\
\hline Depressive feelings (0-24) & $5.03(4.26)$ & & $3.95(3.45)$ & & $* * *$ \\
\hline Self-esteem (0-40) & $29.84(5.54)$ & & $31.43(4.76)$ & & $* * *$ \\
\hline Mastery (0-28) & $19.05(4.33)$ & & $20.35(3.96)$ & & $* * * *$ \\
\hline Life satisfaction $(0-10)$ & $7.63(1.72)$ & & $7.79(1.72)$ & & NS \\
\hline Conflict in marriage prior to divorce $(0-30)$ & $9.56(6.39)$ & & $7.91(5.41)$ & & $* * *$ \\
\hline Conflict in marriage prior to divorce (both) & $8.73(4.65)$ & & $8.73(4.65)$ & & \\
\hline Continued contact with ex-partner & & 80.5 & & 79.8 & NS \\
\hline Current conflict with ex-partner $(0-30)$ & $1.47(2.49)$ & & $1.47(2.38)$ & & NS \\
\hline Current conflict with ex-partner (both) & $1.39(1.92)$ & & $1.39(1.92)$ & & \\
\hline Living with a new partner & & 46.2 & & 54.9 & ** \\
\hline Living with a new spouse & & 15.9 & & 18.4 & NS \\
\hline Living with a new cohabiting partner & & 30.3 & & 36.5 & * \\
\hline Conflict with new spouse & $2.97(3.32)$ & & $2.08(2.39)$ & & NS \\
\hline Conflict with new cohabiting partner & $2.31(2.31)$ & & $2.62(2.79)$ & & NS \\
\hline Age & $42.49(6.67)$ & & $44.41(6.51)$ & & **** \\
\hline Job & & 87.2 & & 90.1 & NS \\
\hline \multicolumn{6}{|l|}{ Education } \\
\hline low & & 16.1 & & 19.5 & NS \\
\hline medium & & 39.2 & & 41.9 & NS \\
\hline high (= ref.cat.) & & 44.4 & & 38.1 & * \\
\hline \multicolumn{6}{|l|}{ Income (equivalent household income, EHI) } \\
\hline no information & & 6.3 & & 8.7 & NS \\
\hline$<50 \%$ & & 7.8 & & 6.3 & NS \\
\hline $50-79 \%$ & & 35.7 & & 26 & $* *$ \\
\hline $80-119 \%$ (= ref.cat.) & & 33.2 & & 32.1 & NS \\
\hline$>=120 \%$ & & 17 & & 26.9 & $* * *$ \\
\hline Minor children with ex-spouse & & 63 & & 60.8 & NS \\
\hline Time since divorce $<3 y$ yrs & & 13.7 & & 15.2 & NS \\
\hline
\end{tabular}

$* * * \mathrm{p}<.001,{ }^{* *} \mathrm{p}<.01,{ }^{*} \mathrm{p}<.05, \mathrm{NS}=$ not significant. 
Figure 2. Estimated means for feelings of depression and life satisfaction of single divorced women versus women in a high conflict-loaded (+2 s.d.) new partner relationship, all else set equal (DIF, 2009-2010) ${ }^{3}$

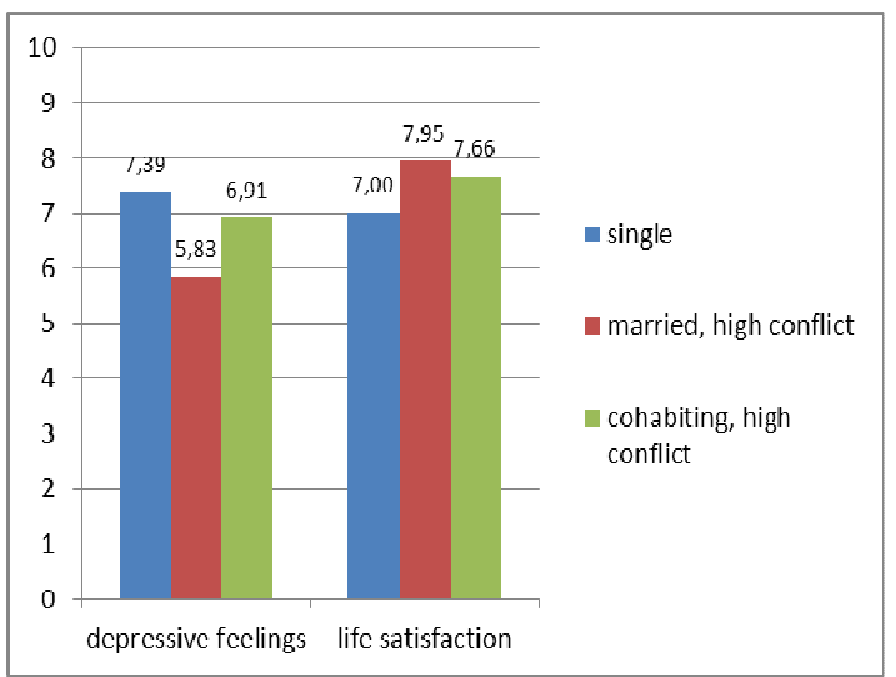

\footnotetext{
${ }^{3}$ Estimated means are calculated using parameter estimates of gender-separate analyses (not shown), using following parameters: mean age, having continued contact with the ex-spouse, mean levels of conflict with the ex-spouse now, and mean levels of conflict with regard to prior marital conflict.
} 
Figure 3. Estimated means for feelings of depression and life satisfaction of single divorced men versus men in a high conflict-loaded $(+2$ s.d.) new partner relationship, all else set equal (DIF, 2009-2010) $)^{4}$

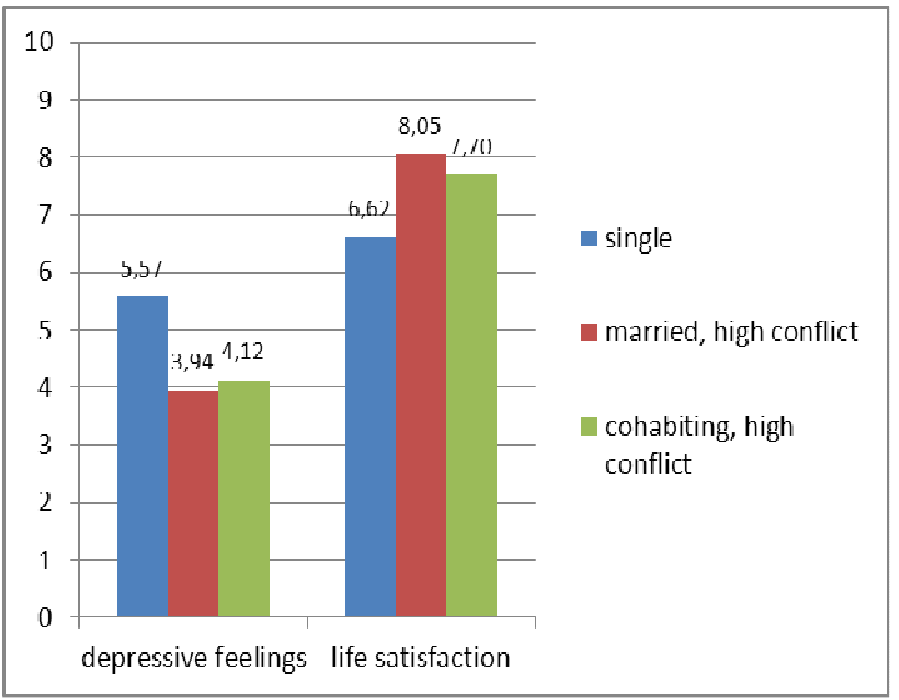

\footnotetext{
${ }^{4}$ Estimated means are calculated using parameter estimates of gender-separate analyses (not shown), using following parameters: mean age, having continued contact with the ex-spouse, mean levels of conflict with the ex-spouse now, and mean levels of conflict with regard to prior marital conflict.
} 
Table 2. The Mental Health of Divorced Men and Women and Conflicts with New Partner and Ex-partner (DIF, 2009-2010)

\begin{tabular}{|c|c|c|c|c|c|c|c|c|c|c|c|c|}
\hline \multirow[b]{2}{*}{ Parameter } & \multicolumn{2}{|c|}{$\begin{array}{l}\text { Depressive feelings } \\
(\mathrm{N}=892)\end{array}$} & \multirow[b]{2}{*}{ Sig. } & \multicolumn{2}{|l|}{$\begin{array}{l}\text { Self-esteem } \\
(\mathrm{N}=892)\end{array}$} & \multirow[b]{2}{*}{ Sig. } & \multicolumn{2}{|l|}{$\begin{array}{l}\text { Mastery } \\
(\mathrm{N}=892)\end{array}$} & \multicolumn{3}{|c|}{$\begin{array}{l}\text { Life satisfaction } \\
(\mathrm{N}=892)\end{array}$} & \multirow[b]{2}{*}{ Sig. } \\
\hline & Estimate & SE & & Estimate & SE & & Estimate & SE & Sig. & Estimate & $\mathrm{SE}$ & \\
\hline Intercept & 4.534 & 1.080 & $* * *$ & 31.311 & 1.525 & $* * *$ & 20.349 & 1.243 & $* * *$ & 8.100 & .464 & **** \\
\hline Men & -.821 & .272 & $* *$ & 1.230 & .381 & $* * *$ & -.090 & .593 & & -.021 & .117 & \\
\hline \multicolumn{13}{|l|}{ New partner $($ single $=$ ref.cat. $)$} \\
\hline New spouse & -2.657 & .436 & $* * *$ & 1.170 & .613 & $(*)$ & -.522 & .653 & & 1.725 & .188 & $* * *$ \\
\hline New cohabiting partner & -2.707 & .351 & $* * *$ & 1.388 & .493 & $* *$ & 1.557 & .392 & $* * *$ & 1.482 & .151 & $* * *$ \\
\hline Conflict with new spouse & .281 & .105 & $* *$ & -.081 & .148 & & -.004 & .119 & & -.189 & .045 & *** \\
\hline Conflict with new cohabiting partner & .703 & .125 & $* * *$ & -.534 & .176 & $* *$ & -.319 & .095 & $* * *$ & -.304 & .054 & *** \\
\hline \multicolumn{13}{|l|}{ Ex-partner } \\
\hline Continued contact with ex-partner & -.351 & .327 & & -.196 & .461 & & -.141 & .367 & & -.193 & .140 & \\
\hline Conflict with ex-partner (both) & .224 & .075 & $* *$ & -.158 & .107 & & -.238 & .085 & $* *$ & -.006 & .032 & \\
\hline Prior marital conflict (both) & -.028 & .028 & & -.042 & .040 & & -.050 & .043 & & .028 & .012 & * \\
\hline Time since divorce $<3 y r s$ & .093 & .358 & & .069 & .505 & & .136 & .401 & & -.214 & .154 & \\
\hline Minor children with ex-spouse & -.085 & .289 & & -.250 & .409 & & -.171 & .324 & & -.149 & .124 & \\
\hline \multicolumn{13}{|l|}{ Education (high = ref.cat.) } \\
\hline Low & .488 & .355 & & -1.868 & .501 & $* * *$ & -.592 & .400 & & -.225 & .153 & \\
\hline Medium & -.120 & .275 & & -.758 & .388 & * & -.017 & .310 & & .096 & .118 & \\
\hline Job & -2.018 & .394 & $* * *$ & 1.519 & .555 & $* *$ & 1.864 & .446 & $* * *$ & .539 & .169 & $* *$ \\
\hline \multicolumn{13}{|l|}{ Income (EHI $80-119 \%=$ ref.cat.) } \\
\hline 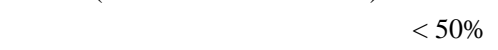 & .893 & .520 & & -1.101 & .732 & & -1.614 & .585 & $* *$ & -.583 & .223 & $* *$ \\
\hline $50-79 \%$ & .629 & .314 & $*$ & -.932 & .442 & $*$ & -.489 & .353 & & -.253 & .135 & $(*)$ \\
\hline$>=120 \%$ & .571 & .337 & & .031 & .475 & & -.044 & .378 & & -.154 & .145 & \\
\hline No information given & .786 & .492 & & -.891 & .692 & & -.242 & .554 & & -.187 & .211 & \\
\hline Age & .063 & .020 & $* *$ & -.031 & .029 & & -.045 & .023 & $*$ & -.030 & .009 & $* * *$ \\
\hline \multicolumn{13}{|l|}{ Interactions } \\
\hline $\begin{array}{l}\text { Men } x \text { conflict with new cohabiting } \\
\text { partner }\end{array}$ & -.265 & .137 & $*$ & .389 & .192 & * & & & & .139 & .059 & $*$ \\
\hline \multicolumn{13}{|l|}{ Variances } \\
\hline Within couples & 12.76 & & & 24.90 & & & 16.09 & & & 2.36 & & \\
\hline Between couples & 0 & & & .33 & & & 0 & & & 0 & & \\
\hline
\end{tabular}


